\title{
RADIOLARIAN PALEOBIOGEOGRAPHY IN NORTHERN EURASIA DURING THE LATE CRETACEOUS-EARLY PALEOGENE
}

AMON , Edward O., Inst. Geol.\&Geochem., UB Russian Acad. Sci., 620151 Ekaterinburg, Russia; BLUEFORD Joyce R., Math/Science Nucleus, Fremont, CA 94538, U.S.A.

During the Late Cretaceous - early Paleogene there is evidence of intensive silica accumulation throughout the northern hemisphere. The silica accumulation is mainly of biogenic origin, but chemical processes also play a major role. Accumulation occurred within sedimentary basins, deep oceans, and along continental margins. Biogenic and chemogenic siliceous rocks of Cretaceous, Paleocene and Eocene age are found in western North America; the Atlantic, Pacific, and Polar Oceans; and northern Eurasia. In northern Eurasia, the majority of the siliceous deposits are located north of $50^{\circ}$ Nlatitude. They can be distinguished in three major silica accumulation provinces: 1) northwest portion of European Russia, dominated by siliceous rocks from lacustrine deposition; 2) marine epicontinental in the east European and West Siberian platform of marine origin; and 3) marginal deposition associated with volcanism in northeast Russia including Kamchatka, Comandor Islands, Sakhalin, and in the northern periphery of the Tethyan belt.

In the eastern European and West Siberian provinces there are certain changes in the radiolarians fauna that correspond to geologic events and to siliceous biogenic rates of accumulation. During the Cenomanian-Turonian, Maastrichtian and Middle Eocene, siliceous accumulation was at a minimum. In the Santonian and early Eocene there was a maximum siliceous accumulation. In the Coniacian, Campanian and Paleocene the siliceous deposition was at medium intensity. The use of radiolarians in this study helps to reconstruct these basins and provides insight on the mode of siliceous deposition. 